\title{
El Principio de prevención de acuerdo al Tribunal de Fiscalización Ambiental: La Resolución 21-2014- OEFA-TFA-SEP1 examinada a la luz del Principio de tipicidad
}

\section{Luis Felipe Huertas del Pino Sebastián Saavedra}

En el presente artículo, los autores realizan un análisis de la importancia del precedente de observancia obligatoria en relación a los alcances del artículo 5 del Reglamento de Protección Ambiental de las Actividades Minero-Metalúrgicas y su relación con las reglas interpretativas del Derecho Peruano en especial el Principio de Tipicidad.

Abogado por la Universidad el Lima, LLM en Derecho y Política Minera por el CEPMLP de la Universidad de Dundee. Socio de Osterling Abogados en el Área de Minería, Recursos Naturales y Medio Ambiente.

** Abogado por la Universidad Peruana de Ciencias Aplicadas. Asociado de Osterling Abogados en el Área de Minería, Recursos Naturales y Medio Ambiente. 


\section{El Principio de prevención de acuerdo al Tribunal de Fiscalización Ambiental: La Resolución 21-2014-OEFA-TFA-SEP1 examinada a la luz del Principio de tipicidad.}

\section{Introducción}

El 14 de noviembre de 2014 la Resolución del Tribunal de Fiscalización Ambiental 212014-OEFA-TFA-SEP1 fue publicada en el Diario Oficial. Esta resolución establece un precedente de observancia obligatoria en relación a los alcances del artículo 5 del Reglamento de Protección Ambiental de las Actividades Minero-Metalúrgicas, aprobado mediante Decreto Supremo 16-93-EM ${ }^{1}$. Aun cuando en la actualidad dicho reglamento ha sido derogado,este precedente es importante porque constituye uno de los primeros de su tipo y porque establece, según el Tribunal de Fiscalización Ambiental, la forma de interpretar una de las normas ambientales más importantes que ha regido al sector minero.

Ahora, el precedente también es importante pues aparentemente no es consistente con las reglas de interpretación normativa más elementales del derecho peruano. Es propósito del presente artículo analizar el referido precedente a la luz de tales reglas, en particular el Principio de tipicidad, y determinar si cumple o no con las mismas.

En cualquier sistema jurídico los precedentes, sean estos de carácter administrativo o judicial, cumplen un rol fundamental. Los precedentes muestran cómo es que las autoridades del sistema (administrativas o judiciales) aplican las normas del sistema a los casos particulares. En el ámbito del derecho administrativo, los precedentes a los que nos referimos no son otra cosa que actos administrativos emitidos por autoridades.

En general, un acto administrativo es el resultado de un análisis legal que efectúa una autoridad con la finalidad de producir efectos jurídicos sobre los intereses, obligaciones o derechos de los administrados dentro de una situación concreta. ${ }^{2}$ Dicho análisis requiere que la autoridad identifique las normas legales que aplican a un caso en particular y que defina las consecuencias que tendrántales normaspara dicho caso en particular.Si bien cualquier resolución puede informar sobre la forma como una autoridad aplica determinadas normas a determinados casos, son sin duda las resoluciones de última instancia administrativa aquellas que nos informan con un carácter más definitivo, pues tales resoluciones agotan la vía administrativa.

1 El Reglamento Ambiental Minero (cuyo nombre completo es Reglamento para la Protección Ambiental de las Actividades Minero Metalúrgicas) fue aprobado mediante Decreto Supremo 016-93-EM.

${ }^{2}$ Ley de Procedimientos Administrativos Generales, numeral 1.1, artículo 1. 
Ahora bien, existe determinado tipo de precedentes que constituyen una fuente de derecho: aquellos que interpretan de modo expreso y con carácter general el sentido de la legislación,estos precedentes son de observancia obligatoria por las entidades de la administración. ${ }^{3}$ Al ser la Resolución 21-2014-OEFA-TFA-SEP1 (en adelante la Resolución), un precedente de observancia obligatoria $y$, por lo tanto, fuente de derecho, resulta entonces pertinente analizar si los criterios interpretativos en los que se basa dicha resolución son consistentes (o no) con las reglas de interpretación normativa que rigen en nuestro sistema. De no serlo, el precedente sería no solo redundante sino perjudicial para el sistema jurídico y, por lo tanto, debería dejarse sin efecto.

Con miras a examinar laResolución 21-2014-OEFA-TFA-SEP1primero describiremos el contenido del referido precedente así como sus fundamentos. Luego visitaremos los conceptos legales que son abordados en el precedente (principalmente los alcances del artículo 5 del Reglamento de Protección Ambiental de las Actividades MineroMetalúrgicas, el cumplimiento de los límites máximos permisibles y el Principio de prevención) y los conceptos teóricos que fundamentan la teoría de la interpretación jurídica. Seguidamente, examinaremos los alcances del Principio de tipicidad para, finalmente, practicar el análisis legal que es el objetivo principal del presente trabajo.

\section{El precedente}

La Resolución 21-2014-OEFA-TFA-SEP1del Tribunal de Fiscalización Ambientalresolvió un recurso de apelación interpuesto por una empresa minera que no estuvo de acuerdo con una multa que le impuso la Dirección de Fiscalización, Sanción y Aplicación de Incentivos, el órgano de primera instancia del OEFA, referida al incumplimiento del artículo 5 del Reglamento de Protección Ambiental de las Actividades Minero-Metalúrgicas. De forma adicional a resolver el pedido de la empresa, declarándolo infundado, la Resolución 21-2014-OEFA-TFA-SEP1estableció un precedente de observancia obligatoria respecto de los alcances del referido artículo 5.

Las razones que motivaron al Tribunal de Fiscalización Ambiental a emitir el precedente de observancia obligatoria están detalladas en el párrafo 80 de la Resolución 21-2014OEFA-TFA-SEP1:

“80. En tal sentido, atendiendo a que en diversos procedimientos administrativos sancionadores referidos al incumplimiento del artículo 50 del Decreto Supremo № 016-93-EM (como en el presente caso), los administrados han cuestionado las obligaciones contenidas en el mismo, y, además, teniendo en consideración que este Tribunal Administrativo ha sostenido de manera reiterada y uniforme que las obligaciones ambientales fiscalizables que subyacen a la citada norma son las consignadas en el

3 Ley del Procedimiento Administrativo General, numeral 1 del artículo VI del Título Preliminar. 
considerando 52, esta Sala Especializada considera relevante que el criterio interpretativo contenido en la presente resolución sea declarado precedente administrativo de observancia obligatoria, permitiendo que las controversias derivadas de los procedimientos administrativos sancionadores en el ámbito de la fiscalización ambiental en el sector minero sean resueltas conforme a aquel, y siendo su aplicación obligatoria por parte de la entidad."

Atendiendo a estas razones, el artículo tercero de la Resolución 21-2014-OEFA-TFASEP1 estableció lo siguiente:

“Tercero.- Declarar que (...) la presente resolución constituye precedente administrativo de observancia obligatoria respecto a la determinación de los alcances del artículo 5o del Decreto Supremo № 016-93-EM, en los siguientes términos:

El artículo 5으 del Decreto Supremo № 016-93-EM impone al titular minero dos obligaciones consistentes en: (i) adoptar con carácter preventivo, las medidas necesarias para evitar e impedir que las emisiones, vertimientos, desechos, residuos $u$ otros que se produzcan como resultado de las actividades realizadas o situaciones generadas en sus instalaciones, puedan tener efectos adversos en el ambiente. Para que se configure el incumplimiento de dicha obligación no es necesario que se acredite la existencia de un daño al ambiente, bastando únicamente la verificación de que el titular minero no adoptó medidas de prevención necesarias en resguardo del ambiente ante una posible afectación como producto de su actividad minera; y, (ii) no exceder los límites máximos permisibles".

Los alcances de la Resolución 21-2014-OEFA-TFA-SEP1bajo comentario son determinantes para quienes hayan ejercido actividades mineras regidas por el artículo 5 delReglamento de Protección Ambiental de las Actividades Minero-Metalúrgicas, pues el texto del referido artículo difiere de manera importante de los alcances establecidos por la Resolución 21-2014-OEFA-TFA-SEP1 del Tribunal de Fiscalización Ambiental, como podemos apreciar a continuación:

"Artículo 5.- El titular de la actividad minero-metalúrgica, es responsable por las emisiones, vertimientos y disposición de desechos al medio ambiente que se produzcan como resultado de los procesos efectuados en sus instalaciones. A este efecto es su obligación evitar e impedir que aquellos elementos $\mathrm{y} / 0$ sustancias que por sus concentraciones $\mathrm{y} / 0$ prolongada permanencia puedan tener efectos adversos en el medio ambiente, sobrepasen los niveles máximos permisibles establecidos."

Una interpretación literal del artículo 5 del Reglamento de Protección Ambiental de las Actividades Minero-Metalúrgicas impide al lector concluir que el titular de la actividad minero-metalúrgica, por mandato de dicha norma, tiene la obligación de adoptar "con carácter preventivo, las medidas necesarias para evitar e impedir que las emisiones, 
vertimientos, desechos, residuos u otros que se produzcan como resultado de las actividades realizadas o situaciones generadas en sus instalaciones, puedan tener efectos adversos en el ambiente." Literalmente, lo único que permite concluir el referido artículo es que el titular de la actividad minero-metalúrgica tiene como obligación que ciertos elementos y/o sustancias no sobrepasen los niveles máximos permisibles establecidos.

Los fundamentos de la Resolución 21-2014-OEFA-TFA-SEP1 bajo comentario justifican cómo a través de la interpretación de diversas normas jurídicas el Tribunal de Fiscalización Ambiental llegó a establecer los alcances expuestos en el artículo tercero de la Resolución 21-2014-OEFA-TFA-SEP1. A continuación examinaremos tales fundamentos.

\section{Los fundamentos del precedente}

Estos fundamentos se encuentran en los párrafos 53 al 59 de la Resolución 21-2014OEFA-TFA-SEP1. A continuación examinaremos los más importantes.Primeramente,la Resolución 21-2014-OEFA-TFA-SEP1señala que el artículo 7 de la Ley General del Ambiente, del año 2005, dispone que las normas ambientales deben ser interpretadas siguiendo los principios y normas contenidos en dicha ley. ${ }^{4} E$ I referido artículo 7 indica:

“Artículo 7ํ.- Del carácter de orden público de las normas ambientales

7.1 Las normas ambientales, incluyendo las normas en materia de salud ambiental y de conservación de la diversidad biológica y los demás recursos naturales, son de orden público. Es nulo todo pacto en contra de lo establecido en dichas normas legales.

7.2 El diseño, aplicación, interpretación e integración de las normas señaladas en el párrafo anterior, de carácter nacional, regional y local, se realizan siguiendo los principios, lineamientos y normas contenidas en la presente Ley $\mathrm{y}$, en forma subsidiaria, en los principios generales del derecho." 5

En efecto, el artículo 5 del Reglamento de Protección Ambiental de las Actividades Minero-Metalúrgicas es una norma ambiental. En tal sentido, la norma citada confirma que dicho artículo es de orden público y que todo pacto en contra de dicha norma es nulo. Asimismo,que su interpretación debe realizarse siguiendo los principios, lineamientos y normas contenidas en la Ley General del Ambiente y, en forma subsidiaria, en los principios generales del derecho.

${ }^{4}$ Párrafo 53 de la Resolución 21-2014-OEFA-TFA-SEP1.

${ }^{5}$ Ley General del Ambiente, artículo 7. 
La Resoluciónagrega que(i) el Principio de Prevención, previsto en el numeral 75.1 del artículo 75 de la Ley General del Ambiente, y la obligación de cumplir con los Límites Máximos Permisibles, prevista en el numeral 32.1 del artículo 32 de la Ley General del Ambiente, se encuentran contempladas en el artículo 5 del Reglamento de Protección Ambiental de las Actividades Minero-Metalúrgicas. Si bien ambas premisas son ciertas, la conclusión no lo es.

Por un lado, el numeral 75.1 del artículo 75 de la Ley General del Ambienteseñala:

“75.1 El titular de operaciones debe adoptar prioritariamente medidas de prevención del riesgo y daño ambiental en la fuente generadora de los mismos, así como las demás medidas de conservación y protección ambiental que corresponda en cada una de las etapas de sus operaciones, bajo el concepto de ciclo de vida de los bienes que produzca o los servicios que provea, de conformidad con los principios establecidos en el Título Preliminar de la presente Ley y las demás normas legales vigentes." 6

Por el otro, el numeral 32.1 del artículo 32 de dicha ley dice:

“32.1 El Límite Máximo Permisible - LMP, es la medida de la concentración - grado de elementos, sustancias o parámetros físicos, químicos y biológicos, que caracterizan a un efluente o una emisión, que al ser excedida causa o puede causar daños a la salud, al bienestar humano y al ambiente. Su determinación corresponde al Ministerio del Ambiente. Su cumplimiento es exigible legalmente por el Ministerio del Ambiente y los organismos que conforman el Sistema Nacional de Gestión Ambiental. Los criterios para la determinación de la supervisión y sanción serán establecidos por dicho Ministerio." 7

Como podemos apreciar, de un examen literal del texto del artículo 5 del Reglamento de Protección Ambiental de las Actividades Minero-Metalúrgicas, éste exige que no se excedan los LMP (en realidad, el artículo 5 se refiere a los niveles máximos permisibles establecidos; pero, como veremos más adelante, se trate de un concepto equivalente a los LMP), mas no contempla exigencia alguna relacionada al Principio de Prevención. Sin perjuicio de lo señalado, la Resolución 21-2014-OEFA-TFA-SEP1 dispone lo siguiente:

“55. Corresponde precisar que el criterio interpretativo sentado por el Tribunal de Fiscalización Ambiental respecto a las obligaciones ambientales fiscalizables que subyacen al artículo 50 del Decreto Supremo № 016-93EM, tiene sustento en el marco del interés público, optimizando con ello la

${ }^{6}$ Ley General del Ambiente, numeral 75.1 del artículo 75.

$7 \quad$ Ley General del Ambiente, numeral 32.1 del artículo 32. Texto del numeral 32.1 según artículo 1 del Decreto Legislativo 1055, publicado el 27 de junio de 2008. 
dimensión objetiva ${ }^{57}$ del derecho fundamental de toda persona a gozar de un ambiente equilibrado y adecuado. En ese sentido, este Tribunal entiende que, en el presente caso, una interpretación literal de la norma no es suficiente para lograr una adecuada protección al derecho materia de análisis, sino que esta debe ser entendida en el trasfondo de su finalidad, que acorde con el ordenamiento jurídico en materia ambiental y con la norma constitucional, es la preservación del ambiente, en cuyo contexto la prevención se erige como un principio fundamenta $\left.\right|^{58} .{ }^{18} \mathrm{El}$ Tribunal de Fiscalización Ambientalreconoce que una interpretación literal del texto del artículo 5 delTribunal de Fiscalización Ambientalno sería suficiente para lograr una adecuada protección al derecho constitucional de las personas a "gozar de un ambiente equilibrado y adecuado", pues soslayaría la aplicación del principio de prevención. En tal sentido, elTribunal de Fiscalización Ambiental efectúa una interpretación finalista del artículo 5 del Reglamento de Protección Ambiental de las Actividades MineroMetalúrgicas para incluir dentro de sus disposiciones al referido principio. Esto se aprecia con claridad en lossiguientes párrafosResolución:

“56. Conforme a lo indicado, el artículo 50 del Decreto Supremo № 016-93EM no solo exige a los titulares mineros no exceder los LMP, sino también adoptar otras medidas de prevención y control a fin de evitar que se causen 0 que se puedan causar efectos adversos al ambiente, lo que sucedería por ejemplo si deja de construir un canal de coronación en los depósitos de relaves para la conducción de las aguas de escorrentía (sin lo cual dichas aguas podrían contaminarse al tener contacto con el material dispuesto en tales depósitos); si deja de implementar un sistema de control de polvos que evite la presencia de emisiones fugitivas que podrán afectar a la zonas aledañas a la planta de beneficio o vías de acceso a su unidad minera; o si no evita o impide la existencia de filtraciones en el dique de las lagunas de estabilización que tratan las aguas residuales domésticas de su unidad minera.

57. En consecuencia, es un contrasentido sostener que la única forma de evitar e impedir que las actividades de explotación minera puedan tener efectos adversos en el ambiente es que los efluentes no excedan los LMP, pues tal como se ha mencionado, existen otras formas a través de las cuales pueden generarse efectos adversos al ambiente. Es por ello que, la exigencia de que los titulares mineros adopten todas las medidas de prevención necesarias a efectos de evitar cualquier afectación al medio ambiente distinta a la ocasionada por el exceso de los LMP ${ }^{59}$, se impone como una interpretación legitima no solo desde la lectura finalista del artículo 50 del Decreto Supremo № 016-93-EM, sino también teniendo en consideración el marco constitucional del numeral 22 del artículo 2ํ de la Norma Fundamental."

Entonces, de esta manera, el Tribunal de Fiscalización Ambiental realiza unalectura 0 interpretación finalista del artículo 5 del Reglamento de Protección Ambiental de las

${ }^{8}$ Párrafo 55 de la Resolución 21-2014-OEFA-TFA-SEP1.

FORSETI

Número 1 
Actividades Minero-Metalúrgicaspara concluir, de manera adicional a lo que una lectura literal sugiere, que dicha norma también exige a los titulares mineros la obligación de "adoptar otras medidas de carácter preventivo".

Para efectuar un estudio apropiado de las reglas de interpretación que resultan aplicables al caso concreto, primero describiremos los conceptos legales que han sido interpretados en aplicación de (o contraviniendo) las referidas reglas.

\section{El Reglamento de Protección Ambiental de las Actividades Minero- Metalúrgicas y la regulación ambientaldel sector minero}

En el Perú, y probablemente en Latinoamérica, existe de manera general un aparente antagonismo entre las nociones de "promoción de la inversión privada" y la "protección del ambiente". Esta apariencia es sin duda más evidente cuando hablamos de inversiones en el sector minero. Los autores creemos que estacircunstancia es la consecuencia de que normalmente se suele asociar a la inversión privada con la derecha política y, por el contrario, a la protección ambiental con la izquierda;donde sí ha existido y aún existe un marcado antagonismo. Si bien en nuestra opiniónla "promoción de las inversiones" y la "protección del ambiente" no son nociones antagónicas por sí mismas, lo cierto es que hoy,por lo menos en el Perú, tenemos que aceptar que se trata de una percepción generalizada.Lo señalado anteriormente no es reciente.Era también una circunstancia que regía el contexto político-regulatorio a inicios de la década de los noventa, cuando el gobierno peruano decidió basar el crecimiento económico del país en la inversión privada. Precisamente la época en la que el Ejecutivo aprobó el Reglamento de Protección Ambiental de las Actividades Minero-Metalúrgicas.Este reglamento fue publicado el 1 de mayo de 1993. Considerando que en Perú la primera norma ambiental, el Código del Medio Ambiente y los Recursos Naturales, se promulgó en el año 1990, el Reglamento de Protección Ambiental de las Actividades Minero-Metalúrgicasestambién una de las normas ambientales peruanas más antiguas. ${ }^{9}$ El Código del Medio Ambiente y los Recursos Naturales fue una de las primeras normas que aprobaron conjuntamente el Ejecutivo y Legislativo elegidos para el periodo $1990-1995 .{ }^{10}$ Si bien las disposiciones delCódigo del Medio Ambiente y los Recursos Naturales, las primeras en materia medioambiental en el país, incorporaron importantes principios, como el Principio de prevención y el Principio contaminador-pagadora la legislación peruana; desde un punto de vista

$9 \quad$ El Código del Medio Ambiente y los Recursos Naturales, Decreto Legislativo 613, es la primera norma ambiental que se dictó en el Perú.

10 Decimos que el Decreto Legislativo 613 fue aprobado "conjuntamente" entre el Ejecutivo y el Legislativo pues para su promulgación el Ejecutivo requirió previamente que el Legislativo le delegue la correspondiente autoridad para legislar. Entonces, no es extraño que nos refiramos a su aprobación como un trabajo "conjunto". 
práctico, la regla más importante del Código del Medio Ambiente y los Recursos Naturalesfue aquella que exigió la aprobación de un Estudio de Impacto Ambiental (EIA) como condición previa para la ejecución de proyectos de obra y actividades, tanto del sector público como del sector privado. ${ }^{11}$

Si bien el Código del Medio Ambiente y los Recursos Naturales tuvo importantes aciertos, dada su aparente generalidad y subjetividad (propias de una legislación novedosa), muchas de sus disposiciones fueron al poco tiempo percibidas como medidas que no aportarían el nivel suficiente de seguridad jurídica que se requería para fomentar y atraer la inversión privada, con lo que tales disposiciones tuvieron que ser modificadas. Esto se puede apreciar con claridad en dos normas aprobadas en 1991: el Decreto Legislativo 708, Ley de Promoción de Inversiones en el Sector Minero y el Decreto Legislativo 757, Ley Marco para el Crecimiento de la Inversión Privada. ${ }^{12}$ En este sentido, el Decreto Legislativo 757 recalcó la necesidad del Estado de estimular el equilibrio racional entre el desarrollo socioeconómico, la conservación del ambiente y el uso sostenido de los recursos naturales, “...garantizando la debida seguridad jurídica a los inversionistas mediante el establecimiento de normas claras de protección del medio ambiente." ${ }^{13}$ Por otro lado, el artículo 14 del Código del Medio Ambiente y los Recursos Naturales contenía una prohibición general de descargar sustancias contaminantes, la cual resultaba sumamente abierta y, por ello, se temía que su aplicación pudiese afectar la seguridad jurídica de la inversiones que se buscaba fomentar; pues si bien el Código del Medio Ambiente y los Recursos Naturalesexigía que las descargas al ambiente generen ciertos niveles tolerables de impactos, dicha norma guardaba silencio sobre (i) qué reglas aplicaban a tales niveles tolerables y (ii) quién sería la autoridad competente para aprobar los mencionados niveles. A efectos de eliminar tales incertidumbres, la Novena Disposición Complementaria Final del Decreto Legislativo 757 estableció lo siguiente:

11 El texto original del artículo 8 del Decreto Legislativo 613 señalaba que la exigencia de unEl A era aplicable a "[t]odo proyecto de obra o actividad, que puede provocar daños no tolerables al ambiente, requiere de un Estudio de Impacto Ambiental (EIA) sujeto a la aprobación de la autoridad competente." Posteriormente, en un claro ejemplo de las medidas de precisión que se adoptaron al poco tiempo de promulgado el Código del Medio Ambiente y los Recursos Naturales, el Decreto Legislativo 757 derogó el artículo 8 y lo sustituyó por el siguiente requerimiento: "La autoridad sectorial competente comunicará al Consejo Nacional del Ambiente - CONAM, sobre las actividades a desarrollarse en su sector, que (...) deberán presentar estudios de impacto ambiental previos a su ejecución...".

12 En tal sentido, el Decreto Legislativo 708 modificó/derogó 10 artículos delCódigo del Medio Ambiente y los Recursos Naturales, mientras que el Decreto Legislativo 757 modificó/derogó 25 artículos de dicha norma.

\footnotetext{
${ }^{13}$ Decreto Legislativo 757, artículo 49.
} 
“Novena.- Toda mención hecha en el Decreto Legislativo № 613, Código del Medio Ambiente y los Recursos Naturales a "autoridades", "autoridad competente" o "autoridad ambiental" se entenderá referida a la autoridad sectorial competente, es decir, al Ministerio del Sector correspondiente a la actividad que se desarrolla.

Asimismo, toda prohibición hecha en dicha norma legal de contaminar el medio ambiente, se entenderá referida a la que exceda los niveles tolerables de contaminación establecidos para cada efluente por la autoridad sectorial competente, tomando en consideración la degradación acumulativa."

Como vemos, hasta que apareció el Decreto Legislativo 757, en el marco regulatorio peruano no existía claridad respecto de cuáles serían las autoridades responsables de implementar y hacer cumplir las recientemente creadas normas ambientales.El referidodecretoasignó a las autoridades sectoriales (es decir, los ministerios titulares de los sectores productivos) dicha responsabilidad. Con el paso del tiempo, a medida las autoridades sectoriales fueron implementando los respectivos marcos regulatorios para cada sector (algunas autoridades con mayor efectividad que otras), el Ejecutivo inició el proceso de fortalecimiento de la autoridad ambiental nacional (hasta ese momento una dependencia de la Presidencia del Consejo de Ministros), hasta convertirla en el año 2008 en el Ministerio del Ambiente.

En este punto vamos a hacer una breve digresión. Como parte del proceso de fortalecimiento mencionado, el Ejecutivo ha venido amalgamando en el Ministerio del Ambiente y sus dependencias, ciertas competencias y funciones que anteriormente pertenecieron a los ministerios. ${ }^{14}$ Recientemente, debido a la contracción de la economía peruana, algunas de estas medidas dieron lugar a preocupaciones en relación a los efectos que podían tener en la promoción y dinamización de las inversiones.Con la finalidad de que tales efectos no sean perjudiciales, el Ejecutivo conjuntamente con el Legislativo emitieron diversas normas correctivas. ${ }^{15}$

De regreso en nuestro tema, fue en el marco de las reformas introducidas por los decretos legislativos 708 y 757 que el MEM aprobó el Reglamento de Protección Ambiental de las Actividades Minero-Metalúrgicas en el año 1993.Los objetivos de dicho reglamento se aprecian a continuación:

14 Algunos ejemplos de tales competencias son: (i) la fiscalización ambiental y la correspondiente imposición de multas en las actividades mineras (sólo mediana y gran minería), eléctricas, de hidrocarburos, pesca y ciertos subsectores específicos de la industria; (ii) la aprobación de las Certificaciones Ambientales que requieran EIA detallados y (iii) la aprobación de los LMP.

15

Concretamente, tales normas fueron el Decreto Supremo 54-2013-PCM, el Decreto Supremo 60-2013-PCM y la Ley 30230. 
"Artículo 3.- Objeto.El presente reglamento tiene por objeto:

a) Establecer las acciones de previsión y control que deben realizarse para armonizar el desarrollo de las actividades minero-metalúrgicas con la protección del medio ambiente.

b) Proteger el medio ambiente de los riesgos resultantes de los agentes nocivos que pudiera generar la actividad minera-metalúrgica, evitando sobrepasen los niveles máximos permisibles.

c) Fomentar el empleo de nuevas técnicas y procesos relacionados con el mejoramiento del medio ambiente."

En aquel año, la fisonomía del sector minero formal era la siguiente: existía un número importante de empresas mineras medianas que tenían operaciones en marcha. Salvo por la excepción de las minas de Toquepala y Cuajone, ambas en manos de una empresa privada, como consecuencia del enfoque estatista que el gobierno peruano implementó en mayor y menor medida entre 1968 y 1990, las operaciones mineras con activos de mayor tamaño o que se percibían "estratégicas" estaban en manos de empresas estatales. Hacia 1990 la gestión de las empresas estatales había sido tan deficiente que su privatización parecía la única manera de obtener reales beneficios económicos de los yacimientos mineros que controlaban. Naturalmente, una de las razones de implementar reglas claras en material ambiental era dotar de la debida seguridad jurídica a las nuevas inversiones.

En tal sentido, el Reglamento de Protección Ambiental de las Actividades MineroMetalúrgicasrequirió la aprobación de un EIA de manera previa a la ejecución de proyectos mineros nuevos.Asimismo, creó un instrumento de gestión específico para las operaciones en curso, denominado Programa de Adecuación y Manejo Ambiental (en adelante PAMA), cuyo propósito era adecuar la realidad de tales operaciones las nuevas normas ambientales. ${ }^{16}$ Conforme podemos apreciar de la definición contenida en el Reglamento de Protección Ambiental de las Actividades Minero-Metalúrgicas, los ElA tenían como propósito principal “...prever los efectos y consecuencias de la realización del proyecto, indicando medidas de previsión y control a aplicar para lograr un desarrollo armónico entre las operaciones de la industria minera y el medio ambiente", es decir, materializar los alcances del Principio de prevención en la gestión ambiental de las actividades mineras. ${ }^{17}$ De manera concordante con dicha definición, el

16 De acuerdo a la definición de PAMA contenida en el RPAAM (artículo 2 del Decreto Supremo 16-93-EM), este instrumento "...contiene las acciones e inversiones necesarias para incorporar a las operaciones minero-metalúrgicas los adelantos tecnológicos y/o medidas alternativas que tengan como propósito reducir o eliminar las emisiones y/o vertimientos para poder cumplir con los niveles máximos permisibles establecidos por la Autoridad Competente."

17 De acuerdo con la definición de EIA contenida en el RPAAM (artículo 2 del Decreto Supremo 16-93-EM), este instrumento representa "[e]studios que deben efectuarse en FORSETI Número 1 
artículo 6 del Reglamento de Protección Ambiental de las Actividades MineroMetalúrgicasseñaló lo siguiente:

“...es obligación del titular poner en marcha y mantener programas de previsión y control contenidos en el Estudio de Impacto Ambiental y/o Programas de Adecuación y Manejo Ambiental, basados en sistemas adecuados de muestreo, análisis químicos, físicos y mecánicos, que permitan evaluar y controlar en forma representativa los afluentes 0 residuos líquidos y sólidos, las emisiones gaseosas, los ruidos y otros que puedan generar su actividad, por cualquiera de sus procesos cuando éstos pudieran tener un efecto negativo sobre el medio ambiente. Dichos programas de control deberán mantenerse actualizados, consignándose en ellos la información referida al tipo y volumen de los afluentes o residuos y las concentraciones de las sustancias contenidas en éstos.

\section{$(\ldots)^{\prime \prime}$}

Por otro lado, el Reglamento de Protección Ambiental de las Actividades MineroMetalúrgicascreó instrumentos para definir los niveles tolerables de riesgo en los efluentes líquidos y las emisiones gaseosas, denominados Niveles Máximos Permisibles. Estos niveles fueron definidos en 1996 para diversos constituyentes potencialmente contaminantes, a través de las resoluciones ministeriales 11-96-EM/VMM y 315-96EM/VMM, luego de un proceso de estudios que abarcó a todas las operaciones mineras, denominado Evaluación Ambiental Preliminar (EVAP), a través del cual se realizó un inventario de las concentraciones de los efluentes y emisiones de las operaciones existentes en el sector. Posteriormente, a partir del año 2005, la Ley General del Ambiente reconoció a los PAMA, ElA y Niveles Máximos Permisibles, entre otros, como instrumentos de gestión ambiental. ${ }^{18} \mathrm{En}$ el caso de los referidos niveles, la Ley General del Ambiente los denominó Límites Máximo Permisibles. ${ }^{19}$ Como podemos ver, los artículos 5 y 6 del Reglamento de Protección Ambiental de las Actividades

proyectos para la realización de actividades en concesiones mineras, de beneficio, de labor general y de transporte minero, que deben evaluar y describir los aspectos físiconaturales, biológicos, socio-económicos y culturales en el área de influencia del proyecto, con la finalidad de determinar las condiciones existentes y capacidades del medio, analizar la naturaleza, magnitud y prever los efectos y consecuencias de la realización del proyecto, indicando medidas de previsión y control a aplicar para lograr un desarrollo armónico entre las operaciones de la industria minera y el medio ambiente."

${ }^{18}$ Ley 28611, artículos 16, 17, 24, 25 y 26.

${ }^{19}$ De acuerdo con la definición contenida en el RPAAM, un Nivel Máximo Permisible es el“[n]ivel de concentración de uno o más contaminantes, por debajo del cual no se prevé riesgo para la salud, el bienestar humano y los ecosistemas." Nótese que tanto el RPAAM como el artículo 32.1 de la Ley General del Ambiente define este concepto como una medida de riesgo. En el caso de la Ley General del Ambienteel elemento de riesgo está definido por la expresión "...que al ser excedido causa o puede causar...". 
Minero-Metalúrgicasdesarrollaron de manera suficiente y satisfactoria los conceptos legales que elTribunal de Fiscalización Ambiental desarrolla en el precedente de observancia obligatoria: el Principio de prevención regulado en el numeral 75.1 del artículo 75 de la Ley General del Ambiente y la obligación de cumplir con los LMP, contemplada en el numeral 32.1 del artículo 32 de laLey General del Ambiente.

\section{La interpretación normativa en el derecho peruano}

La interpretación jurídica constituye una herramienta fundamental en la aplicación del derecho. En tanto el presente artículo aborda un precedente de observancia obligatoria que interpreta de modo expreso y con carácter general el sentido del artículo 5 del Reglamento de Protección Ambiental de las Actividades Minero-Metalúrgicas, resulta fundamental que nos detengamos unos instantes a visitar las consideraciones teóricas más importantes de la interpretación jurídica. Para tal efecto vamos a recurrir al reconocido académico y jurista Marcial Rubio Correa. ${ }^{20}$

Este autor señala que la interpretación jurídica consta de tres componentes: el primero está dado por los "criterios generales de interpretación", los cuales constituyen una aproximación apriorística del interprete sobre la norma a interpretar; el segundo, por los "métodos de interpretación", que son mecanismos operativos de interpretación jurídica generalmente aceptados por la doctrina; y finalmente, el tercer componente estaría dado por los "apotegmas de interpretación", que son argumentos tópicos deaceptación bastante generalizada. ${ }^{21}$ Rubio Correa denomina conjuntamente a estos tres componentes la "teoría de la interpretación jurídica". ${ }^{22}$

A continuación resumiremos lo que señala Rubio Correa sobre los criterios generales y métodos de interpretación pertenecientes a la teoría de la interpretación jurídica:

a. Los criterios generales de interpretación

El autor identifica cuatro criterios fundamentales: el tecnicista, el axiológico, el teleológico y el sociológico. A la luz del criterio tecnicista, el intérprete asume que con la interpretación lo que se busca es conocer el significado de la norma jurídica, pero únicamente a partir del derecho mismo, sin aplicar elementos

20 Para este trabajo visitaremos los conceptos sobre interpretación jurídica que Rubio Correa expone en su conocida obra El Sistema Jurídico, Décima Edición, Fondo Editorial de la Pontificia Universidad Católica del Perú, 2011, pp. 219-257.

21 Rubio Correa, Marcial, El Sistema Jurídico,Décima Edición, Fondo Editorial de la Pontificia Universidad Católica del Perú, 2011, p. 232.

22 Rubio Correa, Marcial, El Sistema Jurídico,Décima Edición, Fondo Editorial de la Pontificia Universidad Católica del Perú, 2011, p. 233. 
diferentes a los estrictamente legales (como la ética, consideraciones sociales, políticas, históricas, etc.) ${ }^{23}$

La aplicación de un criterio axiológico, implica que el intérprete parte de la idea de que la labor interpretativa debe, en la medida de lo posible, adecuar su resultado a ciertos valores que han de imperar en la aplicación del Derecho (como por ejemplo, la justicia, la libertad, la democracia, entre otros.). A diferencia del criterio tecnicista, el criterio axiológico sí hace intervenir elementos extraños a lo propiamente técnico-jurídico en la tarea de interpretación. ${ }^{24}$

El criterio teleológico, también denominado "finalista",implica que el intérprete asume que la interpretación debe ser realizada de manera tal que, en la medida de lo posible, al aplicar la norma jurídica se obtenga una finalidad predeterminada. Para estos efectos, el mismo intérprete o alguna persona 0 autoridad superior a este, debe haber establecido con anterioridad la finalidad que guiará la interpretación. ${ }^{25}$

Finalmente, de acuerdo con el criterio sociológico el intérprete asume que la interpretación debe ser realizada de manera tal que, en la medida de lo posible, la aplicación de la norma jurídica sea adecuada a las características sociales de la realidad normada. ${ }^{26}$

Como vemos, para Rubio Correa, en la aplicación de los diferentes criterios previamente señalados, el intérprete siempre asumirá un punto de partida que orientará la tarea interpretativa. ${ }^{27} \mathrm{En}$ el caso del precedente vinculante que es materia del presente artículo, notamos que el Tribunal de Fiscalización Ambiental se apartó de un criterio puramente tecnisista y optó por un criterio teleológico (o finalista) para sustentar que el artículo 5 del Reglamento de Protección Ambiental de las Actividades Minero-Metalúrgicascontenía la obligación de implementar

23 Rubio Correa, Marcial, El Sistema Jurídico, Décima Edición, Fondo Editorial de la Pontificia Universidad Católica del Perú, 2011, p. 233-234.

${ }^{24}$ Rubio Correa, Marcial, El Sistema Jurídico, Décima Edición, Fondo Editorial de la Pontificia Universidad Católica del Perú, 2011, p. 235.

25 Rubio Correa, Marcial, El Sistema Jurídico, Décima Edición, Fondo Editorial de la Pontificia Universidad Católica del Perú, 2011, p. 235-236.

26 Rubio Correa, Marcial, El Sistema Jurídico, Décima Edición, Fondo Editorial de la Pontificia Universidad Católica del Perú, 2011, p. 236.

27 Rubio Correa, Marcial, El Sistema Jurídico, Décima Edición, Fondo Editorial de la Pontificia Universidad Católica del Perú, 2011, p. 236. 
ciertas medidas de prevención de forma adicional a la obligación de no exceder los LMP.

Salvo ciertas excepciones, como veremos más adelante, en general no existen limitaciones legales para que las autoridades asuman criterios de interpretación axiológicos o teleológicos (e inclusive sociológicos, aunque esto puede ser controversial), siempre que la Resolución 21-2014-OEFA-TFA-SEP1 incorpore la motivación respectiva. ${ }^{28}$ No obstante, en el caso específico de la Resolución 21 2014-OEFA-TFA-SEP1no compartimos que la finalidad del artículo 5 delReglamento de Protección Ambiental de las Actividades MineroMetalúrgicashaya sido obligar a los titulares de la actividad minera a implementar medidas de prevención pues, de la lectura del referido reglamento, dicha obligación se aprecia de manera muy clara en el artículo 6, que señala que es obligación del titular minero poner en marcha y mantener programas de previsión y control contenidos en el El A y/o el PAMA.

b. Los métodos de interpretación

Rubio Correa señala que los métodos de interpretación son procedimientos metodológicos cuyo objetivo es obtener conclusiones positivas respecto al "que quiere decir'la norma jurídica, con la finalidad de conocer su contenido. El autor identifica diversos métodos, entre ellos, el método literal, el método de la ratio legis, el método sistemático por comparación con otras normas, el método sistemático por ubicación de la norma en el sistema, el método histórico y el método sociológico.

Para efectos del presente trabajo nos concentraremos en el método literal. Este método consiste, de acuerdo con Rubio Correa, en averiguar lo que la norma denota mediante el uso de las reglas lingüísticas propias al entendimiento común del lenguaje escrito en el que se halla producida la norma. ${ }^{29}$ Naturalmente, la aplicación del método literal se sustentará en que el intérprete parte de un criterio tecnicista, buscando conocer el contenido último de la norma, a partir de la redacción literal de la misma. Rubio Correa señala que si bien no existe un orden jerárquico entre los distintos métodos de interpretación, sí se acepta que la aplicación del método literal debe ser el punto de partida para conocer el "que quiere decir" de la norma.

28 La motivación de las resoluciones es uno de los principios de la administración jurisdiccional reconocidos en la Constitución (numeral 5, artículo 139), el cual se extiende a la función administrativa por mandato de la Ley del Procedimiento Administrativo General(numeral 1.2 del artículo IV del Título Preliminar y artículo 3).

${ }^{29}$ Rubio Correa, Marcial, El Sistema Jurídico, Décima Edición, Fondo Editorial de la Pontificia Universidad Católica del Perú, 2011, p. 238. 
No obstante, según el autor, resulta posible encontrar un escenario en que la aplicación del método literal no sea suficiente por sí mismo para desentrañar el contenido de la norma. En casos como éste, dice Rubio Correa, será necesario recurrir a otros métodos de interpretación ${ }^{30}$.

A continuación visitaremos dos clases de conceptos esenciales que, a decir de Rubio Correa, son bastante difundidos en el ámbito de la teoría de la interpretación jurídica: cuando la interpretación se efectúa según el intérprete y cuando la interpretación se efectúa según el resultado ${ }^{31}$.

En la primera clase, es decir, cuando la interpretación se efectúa según el intérprete, encontramos: (i) la interpretación auténtica, que corresponde a la autoridad competente para dictar o derogar la norma, siguiendo el mismo procedimiento que adoptó para la emisión de la norma bajo interpretación (como por ejemplo cuando se emite un Decreto Supremo que explica el contenido de otro Decreto Supremo); (ii) la interpretación jurisprudencial, que es la que realiza los tribunales jurisdiccionales (y administrativos) y se traduce en la jurisprudencia como fuente del derecho; y (iii) la interpretación doctrinal, que es hecha por personas que, sin ser autoridades estatales, realizan la interpretación confines académicos.Como podemos evidenciar con mucha facilidad, el precedente objeto de estudio cae en la categoría de interpretación jurisprudencial dado que, como hemos visto, el criterio interpretativo del Tribunal de Fiscalización Ambientalen la Resolución 21-2014-OEFA-TFA-SEP1 ha generado, una fuente de derecho a decir dela Ley del Procedimiento Administrativo General, Ley 27444, pues interpreta de modo expreso y con carácter general el sentido de la legislación, convirtiendo su aplicación en obligatoria por las entidades de la administración.En la segunda clase, cuando la interpretación se efectúa según el resultado, encontramos (i) una interpretación estricta, cuando se aplica el método literal sin ninguna otra consideración externa adicional; (ii) una interpretación extensiva, cuando la conclusión de la norma respecto a su contenido es aplicada a otros casos adicionales a los especificados en su tenor literal; y (iii) una interpretación restrictiva, cuando, las conclusiones interpretativas de la norma aplican única y exclusivamente a los supuestos previstos en esta.En este punto, nos detendremos a examinar lo que sucede con la Resolución 21-2014-OEFA-TFA-SEP1bajo estudio. Claramente, en función al resultado, dicha resolución contiene una interpretación extensiva pues el Tribunal de Fiscalización Ambientalatribuye al artículo 5 del Reglamento de Protección Ambiental de las Actividades Minero-Metalúrgicas obligaciones que no se encuentran contempladas textualmente en dicha norma. En

\footnotetext{
${ }^{30}$ Rubio Correa, Marcial, El Sistema Jurídico, Décima Edición, Fondo Editorial de la Pontificia Universidad Católica del Perú, 2011, p. 239-240.

31 Rubio Correa, Marcial, El Sistema Jurídico, Décima Edición, Fondo Editorial de la Pontificia Universidad Católica del Perú, 2011, p. 256.
} 
efecto, de una interpretación literal del artículo 5 del Reglamento de Protección Ambiental de las Actividades Minero-Metalúrgicasno resulta posible concluir que el titular de la actividad minero-metalúrgica, por mandato de dicha norma, tiene la obligación de adoptar "con carácter preventivo, las medidas necesarias para evitar e impedir que las emisiones, vertimientos, desechos, residuos u otros que se produzcan como resultado de las actividades realizadas o situaciones generadas en sus instalaciones, puedan tener efectos adversos en el ambiente." Al respecto, el párrafo 55 de lala Resolución 21-2014-OEFA-TFA-SEP1reconoce que el método literal no sería, a juicio del Tribunal de Fiscalización Ambiental, suficiente para lograr una adecuada protección al derecho fundamental de toda persona de gozar de una ambiente equilibrado y adecuado, por lo que el Tribunal de Fiscalización Ambientaljustifica la exigibilidad de la referida obligación a través de una interpretación finalista.La situación descrita reviste singular importancia, pues al ser la Resolución 21-2014-OEFA-TFASEP1 un acto que impone una sanción a un administrado, le corresponde estar sujeta a los principios del derecho sancionador $y$, en particular, al Principio de tipicidad. A continuación examinaremos los alcances del referido principio y su aplicación al precedente bajo estudio.

\section{El Principio de tipicidad como estándar para analizar legalmente la Resolución 21-2014-OEFA/ TFA-SEP1}

Este principio se encuentra regulado en el artículo 230 de la Ley del Procedimiento Administrativo General:

“Artículo 230.- (...)

La potestad sancionadora de todas las entidades está regida adicionalmente por los siguientes principios especiales:

( ...)

4. Tipicidad.- Sólo constituyen conductas sancionables administrativamente las infracciones previstas expresamente en normas con rango de ley mediante su tipificación como tales, sin admitir interpretación extensiva 0 analogía. Las disposiciones reglamentarias de desarrollo pueden especificar - graduar aquéllas dirigidas a identificar las conductas o determinar sanciones, sin constituir nuevas conductas sancionables a las previstas legalmente, salvo los casos en que la ley permita tipificar por vía reglamentaria."

Como vemos, la prohibición de la interpretación extensiva o analogía en la determinación de las conductas sancionables administrativamente colisiona frontalmente con el trabajo interpretativo que el Tribunal de Fiscalización 
Ambientalrealizó en la Resolución 21-2014-OEFA-TFA-SEP1. ${ }^{32}$ Pero, si el Principio de tipicidad es categórico al excluir la posibilidad de efectuar interpretaciones extensivas 0 analogías en el momento en que las entidades administrativas ejercen su potestad sancionadora, ¿por qué el Tribunal de Fiscalización Ambientaltomó la decisión de ir, aparentemente, en contra de dicho principio? Las razones que el propio tribunal expone son cinco. A continuación las examinaremos una a una.En primer lugar, el tribunal señala que el artículo 5 del Reglamento de Protección Ambiental de las Actividades Minero-Metalúrgicas, como todas las normas ambientales son de orden públicoy que todo pacto en contra de dichas normas es nulo. Asimismo, que su interpretación debe realizarse siguiendo los principios, lineamientos y normas contenidas en la Ley General del Ambiente y, en forma subsidiaria, en los principios generales del derecho. Al respecto, consideramos que una lectura literal del referido artículo 5 no es contraria ni atenta contra la calidad de orden público que tienen las normas ambientales, pues dicha norma contiene un mandato que es completamente pacífico con nuestra legislación.En particular, con el numeral 32.1 del artículo 32 de la Ley General del Ambiente, que establece que LMP son de obligatorio cumplimiento. Aceptar lo señalado no deja de lado los principios de la Ley General del Ambienteen general (ni los principios generales del derecho), ni el Principio de prevención en particular.

En segundo lugar, consideramos que el artículo 5 del Reglamento de Protección Ambiental de las Actividades Minero-Metalúrgicastampoco es contrario al Principio de prevención establecido en el numeral 75.1 del artículo 75 de la Ley General del Ambiente, el cual señala que los titulares de las actividades deben adoptar prioritariamente medidas de prevención del riesgo y daño ambiental en la fuente generadora de los mismos, así como las demás medidas de conservación y protección ambiental que corresponda en cada una de las etapas de sus operaciones. En nuestra opinión,el artículo 5 del Reglamento de Protección Ambiental de las Actividades Minero-Metalúrgicasno soslaya dicho principio pues su finalidad es la mencionada en el párrafo anterior. Por el contrario, la norma del Reglamento de Protección Ambiental de las Actividades Minero-Metalúrgicasque desarrolla el Principio de prevención claramente es el artículo 6, cuyo texto hemos citado íntegramente más arriba.

En tercer lugar, elTribunal de Fiscalización Ambiental indica que su criterio respecto de las obligaciones ambientales fiscalizables que subyacen al artículo 5del RPAAAM tiene sustento en el marco del interés público, optimizando con ello la dimensión objetiva del

\footnotetext{
${ }^{32}$ Doctrinaria y jurisprudencialmente encontramos unanimidad en la aceptación de la rigidez de la prohibición de la interpretación extensiva o analogía para determinar conductas sancionables administrativamente. Al respecto conviene leer: Morón Urbina, Juan Carlos, Comentarios a la Ley del Procedimiento Administrativo General, Décima Edición, 2014, Gaceta Jurídica, p. 765-773; y las sentencias del Tribunal Constitucional recaídas en los expedientes 535-2009-PA/TC y 1873-2009-PA/TC.
} 
derecho fundamental de toda persona a gozar de un ambiente equilibrado y adecuado. En línea con lo ya señalado, consideramos que una interpretación literal del artículo 5 del Reglamento de Protección Ambiental de las Actividades Minero-Metalúrgicasno atenta contra el interés público debido a que, por un lado, el cumplimiento de los LMP es propiamente una disposición legal de orden e interés públicos.Por otro lado, elReglamento de Protección Ambiental de las Actividades Minero-Metalúrgicas materializa el Principio de prevención expresamente a través de su artículo 6, el cual estuvo vigente y pudo ser invocado por la dependencia de OEFA que resolvió en primera instanciael procedimiento administrativo sancionador que dio origen a la Resolución 21-2014-OEFA-TFA-SEP1.

Al mismo tiempo, el Principio de tipicidad contenido en laLey del Procedimiento Administrativo General es la manifestación a nivel legal de uno de los derechos constitucionales más relevantes: el de no ser procesado ni condenado por uno o más actos $u$ omisiones que al tiempo de cometerse no hayan estado previamente calificados en la ley, de manera expresa e inequívoca, como infracciones punibles; ni sancionado con pena no prevista en la ley. ${ }^{33} \mathrm{En}$ tal sentido, consideramos que la aplicación del Principio de tipicidad en el presente caso encuentra respaldo constitucional de igual manera que el derecho a gozar de un ambiente equilibrado, el cual se encuentra expresamente desarrollado en el Reglamento de Protección Ambiental de las Actividades Minero-Metalúrgicas, tanto a nivel: (i) del cumplimiento de los LMP, a través de la obligación contenida en el artículo 5; y, (ii) del Principio de prevención, a través de la obligación contenida en el artículo 6del Reglamento de Protección Ambiental de las Actividades Minero-Metalúrgicas. De conformidad con lo señalado, consideramos entonces que la siguiente frase del párrafo 55de la Resolución 21-2014-OEFA/TFA-SEP1carece de respaldo legal y constitucional:

“(...) En ese sentido, este Tribunal entiende que, en el presente caso, una interpretación literal de la norma no es suficiente para lograr una adecuada protección al derecho materia de análisis, sino que esta debe ser entendida en el trasfondo de su finalidad, que acorde con el ordenamiento jurídico en materia ambiental y con la norma constitucional, es la preservación del ambiente, en cuyo contexto la prevención se erige como un principio fundamental."

Simplemente, la finalidad del artículo 5 del Reglamento de Protección Ambiental de las Actividades Minero-Metalúrgicas era que los titulares mineros cumplan con los LMP de aquellas sustancias que, por susconcentraciones y/o prolongada permanencia podrían tener efectos adversos en el medio ambiente. Si la dependencia de OEFA que resolvió en primera instancia el procedimiento administrativo sancionador, quería imponer una sanción administrativa como consecuencia de un supuesto incumplimiento de la obligación de implementar medidas de previsión y control contenidas en el ElA y/o

\footnotetext{
${ }^{33}$ Constitución Política de 1993, artículo 2, numeral 24, literal d.
} 
PAMA, lo que debió hacer es imputar el artículo 6 del Reglamento de Protección Ambiental de las Actividades Minero-Metalúrgicas como la norma supuestamente infringida. Lo que no se debió hacer, ni por dicha dependencia ni por el Tribunal de Fiscalización Ambiental, es interpretar extensivamente el artículo 5 del Reglamento de Protección Ambiental de las Actividades Minero-Metalúrgica para aplicar una sanción, pues con ello claramente se infringe el Principio de tipicidad establecido en la Ley del Procedimiento Administrativo General.

En cuarto lugar, elTribunal de Fiscalización Ambiental señala que es un contrasentido sostener que la única forma de evitar e impedir que las actividades de explotación minera puedan tener efectos adversos en el ambiente es que los efluentes no excedan los LMP, pues existirían otras formas a través de las cuales pueden generarse efectos adversos al ambiente. Estamos de acuerdo con el tribunal en que el cumplimiento de los LMP no es la única forma de evitar e impedir que las actividades de explotación minera puedan tener efectos adversos en el ambiente. No obstante, estamos completamente en desacuerdo con el tribunal en que el único lugar de la legislación peruana donde se encuentran reguladas dichas formas sería el artículo 5 del Reglamento de Protección Ambiental de las Actividades Minero-Metalúrgicas. Para cualquier efecto, el artículo 6 de dicho reglamento establecía la obligación del titular minero de poner en marcha y mantener programas de previsión y control contenidos en el EIA y/o PAMA, con lo que no resulta necesario recurrir a una interpretación extensiva del artículo 5, la cual infringe el Principio de tipicidad. Finalmente, de acuerdo al párrafo 80 de la Resolución 21-2014-OEFA-TFA-SEP1, el Tribunal de Fiscalización Ambientaljustifica su actuar en el hecho que resultaba necesario declarar el precedente de observancia obligatoria, “...permitiendo que las controversias derivadas de los procedimientos administrativos sancionadores en el ámbito de la fiscalización ambiental en el sector minero sean resueltas conforme a aquel..." en vista de que en diversos procedimientos administrativos sancionadores referidos al incumplimiento del artículo 5 del Reglamento de Protección Ambiental de las Actividades Minero-Metalúrgicasciertos administrados habían cuestionado las obligaciones contenidas en el mismo, y, además, porque el Tribunal de Fiscalización Ambientalya habíasostenido de manera reiterada y uniforme que las obligaciones ambientales fiscalizables que subyacen a la citada norma son las consignadas en el párrafo 52 de la referida resolución.

Naturalmente, este motivo nos parece el menos valedero de todos, puesto que el hecho de que el Tribunal de Fiscalización Ambientalhaya vulnerado reiteradamente el Principio de tipicidad al validar la interpretación extensiva del artículo 5 del Reglamento de Protección Ambiental de las Actividades Minero-Metalúrgicas, no lo habilita para emitir un precedente de observancia obligatoria que: (i) vulnera abiertamente el Principio de tipicidad, y (ii) tiene como propósito convalidar otros actos que también vulneraron el referido principio. 
Motivaciones como las del precedente bajo estudio dotan de argumentos a quienes sostienen que el antagonismo entre el fomento de la inversión privada y la protección del medio ambiente es real y no algo aparente, lo cual es un despropósito. Lo que el Tribunal de Fiscalización Ambientaldebió hacer en vez de emitir el precedente de observancia obligatoria es declarar nulos todos aquellos procedimientos donde se interpretó extensivamente el artículo 5 del Reglamento de Protección Ambiental de las Actividades Minero-Metalúrgicascomo sustento para imponer una sanción administrativa yordenar que se instruyan nuevamente tales procedimientos(los cuales debieron ser instruidos en el marco del artículo 6 del Reglamento de Protección Ambiental de las Actividades Minero-Metalúrgicas, en lo que fuere aplicable).Si bien lo anterior hubiese significado un gran esfuerzo por parte de las dependencias de OEFA, ello hubiese: (i) reforzado la correcta aplicación de las normas ambientales existentes; (ii) evitado la generación de precedentes de observancia obligatoria que vulneran unprincipioelemental del procedimiento administrativo sancionador, y (iii) contribuido a que se genere mayor confianza respecto de las instancias administrativas del Ministerio del Ambiente en su relación con el fomento de la inversión privada.

\section{I. El nuevo reglamento ambiental para las actividades mineras}

Al inicio del presente artículo adelantamos que el Reglamento de Protección Ambiental de las Actividades Minero-Metalúrgicas, incluyendo los artículos 5 y 6 , había sido derogado. Efectivamente, el Decreto Supremo 40-2014-EM derogó el Reglamento de Protección Ambiental de las Actividades Minero-Metalúrgicas con lo cual se sustituyó la regla del artículo 5 por la siguiente:

“Artículo $16^{\circ}$.- De la responsabilidad ambiental

El titular de la actividad minera es responsable por las emisiones, efluentes, vertimientos, residuos sólidos, ruido, vibraciones y cualquier otro aspecto de sus operaciones, así como de los impactos ambientales que pudieran generarse durante todas las etapas de desarrollo del proyecto, en particular de aquellos impactos y riesgos que excedan los Límites Máximos Permisibles y afecten los Estándares de Calidad Ambiental, que les sean aplicables 0 afecten al ambiente y la salud de las personas.

Consecuentemente el titular de la actividad minera debe adoptar oportunamente las medidas de prevención, control, mitigación, recuperación, rehabilitación o compensación en términos ambientales, cierre y post cierre que correspondan, a efectos de evitar o minimizar los impactos ambientales negativos de su actividad y potenciar sus impactos positivos."

Si bien la interpretación jurisprudencial del Tribunal de Fiscalización Ambientalestá limitada para todos aquellos procedimientos administrativos sancionadores donde sea aplicable el artículo 5 del Reglamento de Protección Ambiental de las Actividades Minero-Metalúrgicas (y no el artículo 16 del nuevo reglamento) aún son numerosos los 
El Principio de prevención de acuerdo al Tribunal de Fiscalización Ambiental: La Resolución 21-2014-OEFA-TFA-SEP1 examinada a la ตู่FORSETI luz del Principio de tipicidad

expedientes pendientesde resolver en etapa administrativa y judicial donde se discutirá la legalidad de la interpretación jurisprudencial delTribunal de Fiscalización Ambiental. 